\title{
Endoscopic Ultrasound-Guided Pancreatobiliary Endoscopy in Surgically Altered Anatomy
}

\author{
Pichamol Jirapinyo and Linda S. Lee \\ Brigham and Women's Hospital, Harvard Medical School, Boston, MA, USA
}

Endoscopic retrograde cholangiopancreatography (ERCP) has become the mainstay of therapy for pancreatobiliary diseases. While ERCP is safe and highly effective in the general population, the procedure remains challenging or impossible in patients with surgically altered anatomy (SAA). Endoscopic ultrasound (EUS) allows transmural access to the bile or pancreatic duct (PD) prior to ductal drainage using ERCP-based techniques. Also known as endosonography-guided cholangiopancreatography (ESCP), the procedure provides multiple advantages over overtube-assisted enteroscopy ERCP or percutaneous or surgical approaches. However, the procedure should only be performed by endoscopists experienced in both EUS and ERCP and with the proper tools. In this review, various EUS-guided diagnostic and therapeutic drainage techniques in patients with SAA are examined. Detailed step-by-step procedural descriptions, technical tips, feasibility, and safety data are also discussed. Clin Endosc 2016;49:515-529

Key Words: Endoscopic ultrasound; Surgically altered anatomy; Rendezvous; Antegrade drainage; Transmural drainage

\section{INTRODUCTION}

As advances continue in surgical treatment for obesity, peptic ulcer disease, and gastric and pancreatobiliary malignancies, the number of patients with surgically altered anatomy (SAA) encountered by gastroenterologists will continue to grow. Management of pancreatobiliary diseases usually involves the performance of endoscopic retrograde cholangiopancreatography (ERCP). While the technical success rate for ERCP in the general population is as high as $90 \%,{ }^{1}$ success in patients with SAA may be as low as 55\%, with complication rates as high as $20 \%{ }^{2-4}$ The reasons for failure are multifactorial, and include difficulty reaching the papilla due to the distance and acute angulations along the surgically altered path. Additionally, cannulation of the papilla is usually challenging,

Received: October 10, 2016 Accepted: November 5, 2016

Correspondence: Linda S. Lee

Division of Gastroenterology, Brigham and Women's Hospital, 75 Francis Street, Boston, MA 02115, USA

Tel: +1-617-278-0359, Fax: +1-617-525-8740, E-mail: 1slee@partners.org

cc This is an Open Access article distributed under the terms of the Creative Commons Attribution Non-Commercial License (http://creativecommons.org/ licenses/by-nc/3.0) which permits unrestricted non-commercial use, distribution, and reproduction in any medium, provided the original work is properly cited. and in patients with an anastomosis, even identification of the papilla may be difficult.

Alternative ductal decompression options include percutaneous, surgical, and advanced endoscopic drainage. Percutaneous and surgical approaches are invasive, may require multiple treatment sessions, and are not appropriate in all patients. For example, percutaneous drainage is relatively contraindicated in patients with significant ascites, obesity, and/ or nondilated bile or pancreatic duct (PD). The procedure is also associated with skin infection, bile leak, and drain care. A surgical approach is more invasive and may not be feasible in severely ill patients with multiple comorbidities. Alternatively, overtube-assisted enteroscopy ERCP may be used to improve the success rate of ERCP in patients with SAA to as high as $74 \% .{ }^{5}$ However, the procedure is labor-intensive with a relatively unreliable rate of successfully reaching and cannulating the papilla.

Over the past decade, endoscopic ultrasound (EUS) has rapidly evolved from a simple diagnostic procedure to a powerful therapeutic tool. It has been increasingly used to guide access to the biliopancreatic system prior to further interventions, especially in cases when cannulation fails or when the papilla is inaccessible. This article reviews common types of 
SAA and challenges faced by endoscopists during conventional endoscopy. Tools and techniques used for EUS-guided biliopancreatic access and intervention are then reviewed along with relevant feasibility and safety data.

\section{COMMON TYPES OF SURGICALLY ALTERED ANATOMY}

Common types of SAA currently encountered by gastroenterologists include Billroth II, Roux-en-Y gastric bypass (RYGB), and the Whipple procedure. These surgeries usually result in a long afferent limb of small bowel and acute angulation or stenosis at the anastomosis, which often render endoscopic access to the papilla or anastomosis more challenging. ${ }^{6,7}$

\section{Billroth II anatomy}

The Billroth II procedure was first performed by Billroth in $1885 .{ }^{8}$ It is used to treat gastric cancer or peptic ulcer disease, and consists of subtotal distal gastrectomy. The proximal stomach is then connected to the proximal jejunum in an end-to-side fashion. The afferent limb refers to the duodenum and proximal jejunum, into which biliary and pancreatic secretions drain, while the efferent limb refers to the opposite end, which extends distally (Fig. 1A).

Due to the angle and adhesions, intubation of the afferent limb may be difficult with standard endoscopes, notwithstanding a duodenoscope for ERCP. Upon reaching the ampulla, the orientation is reversed with the bile duct located at the 5 to 6 oclock position, making cannulation a challenge. A Billroth II papillotome, a standard sphincterotome trained in the opposite direction, or a straight catheter may be used to cannulate the bile duct. Sphincterotomy may be performed with the Billroth II papillotome or by using a needle knife to cut over a plastic stent.

\section{Roux-en-Y gastric bypass anatomy}

First described by Mason and Ito in 1967, ${ }^{9}$ RYGB had been the most commonly performed bariatric operation in the U.S. until $2013 .{ }^{10}$ During RYGB, the stomach is divided into a small 20-30 mL proximal pouch and a larger distal remnant stomach. The jejunum is divided at 30 to $50 \mathrm{~cm}$ from the ligament of Treitz. The distal portion of the divided jejunum is anastomosed to the pouch at the gastrojejunal (GJ) anastomosis to become a Roux limb. The remnant stomach remains connected to the duodenum and proximal jejunum, which is now termed a biliopancreatic limb and serves to drain pancreatic and biliary secretions. The biliopancreatic and Roux limbs are connected at the jejunojejunal (JJ) anastomosis approximately 75 to $150 \mathrm{~cm}$ from the GJ anastomosis (Fig. 1B).

Endoscopic examination of the pancreatobiliary system in patients with RYGB poses many challenges. As in the case of patients who have undergone the Billroth II procedure, identification and intubation of the afferent limb may be difficult. Moreover, to gain access to the pancreatobiliary area, an endoscope (often a device-assisted enteroscope) must traverse down the Roux limb and up the biliopancreatic limb. This is often technically difficult due to the combined length of the two limbs (at least $>100 \mathrm{~cm}$ ), the angulation of the JJ anastomosis (up to 180 degrees), and adhesions from surgery, all of which may hinder intubation of the biliopancreatic limb and attaining access to the ampulla. If the ampulla is reached, further challenges await during cannulation. With device-assisted enteroscopy ERCP, cannulation requires special long accessories, which are used without the aid of an elevator and often in difficult positions outside the ampulla.
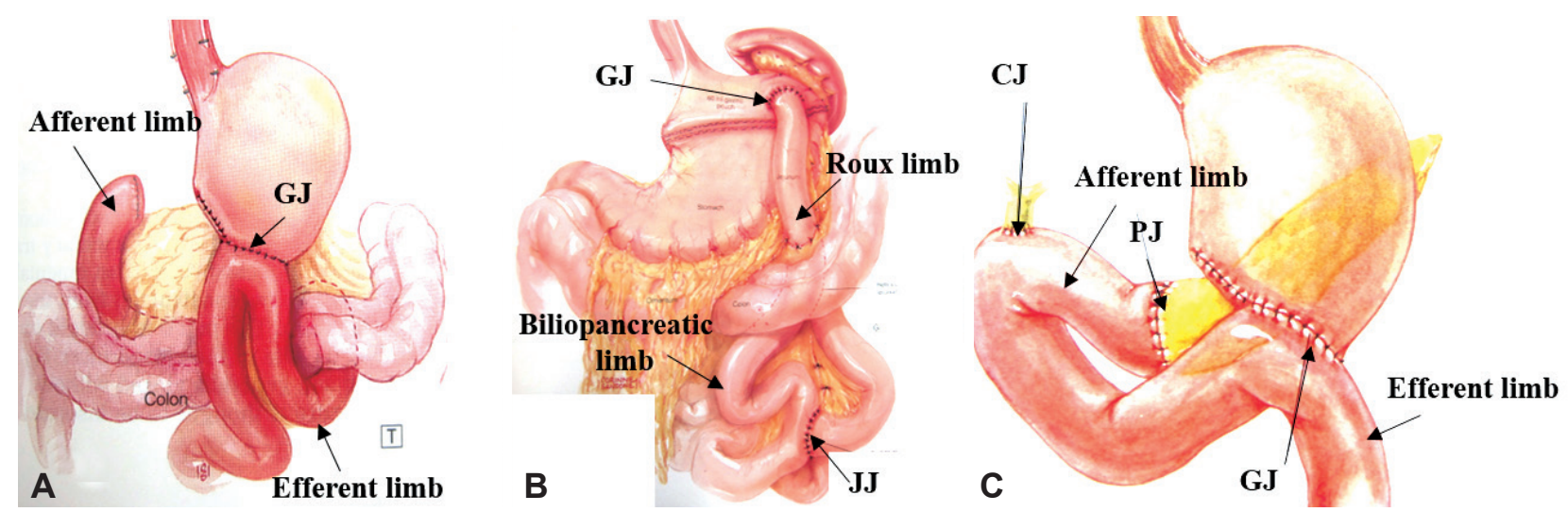

Fig. 1. Common surgically altered anatomy (SAA). (A) Billroth II anatomy (Adapted from Cameron JL. ${ }^{11}$ ). (B) Roux-en-Y gastric bypass (RYGB) anatomy (Adapted from Cameron JL. ${ }^{11}$ ). (C) Pancreaticoduodenectomy (Whipple) anatomy (Adapted from Johnes DB et al. ${ }^{12}$ ). GJ, gastrojejunal; JJ, jejunojejunal; PJ, pancreaticojejunostomy; CJ, choledochojejunal. 


\section{Whipple anatomy}

The Whipple procedure, also known as pancreaticoduodenectomy, was originally described by Codivilla in $1898 .{ }^{13}$ In 1935, Whipple reported an improved version of the surgery and subsequently developed multiple refinements to his technique. ${ }^{14}$ Typically used to treat cancer or precancerous lesions at the head of the pancreas, common bile duct (CBD), ampulla of Vater, or duodenum near the pancreas, the Whipple procedure consists of distal gastrectomy and removal of the pancreatic head, duodenum, proximal jejunum, CBD, and gallbladder. Reconstruction consists of attaching the pancreas to the jejunum (pancreaticojejunostomy [PJ]), the common hepatic duct to the jejunum (choledochojejunostomy), and the stomach to the jejunum (gastrojejunostomy). The afferent limb refers to the portion of the jejunum between the gastrojejunostomy and PJ sites, and is usually 40 to $60 \mathrm{~cm}$ in length (Fig. 1C).

As in other types of SAA, performing endoscopic examination of the pancreatobiliary system in post-Whipple patients is challenging. The same issues arise, including the identification and intubation of the afferent limb and attaining access to the choledochojejunostomy or PJ. Achievement of these goals may be limited by limb angulation and adhesions. An additional challenge involves identification of the choledochojejunostomy or PJ followed by cannulation.

\section{DIAGNOSTIC EUS IN SURGICALLY ALTERED ANATOMY}

\section{Tools}

Similar to standard EUS examination, a radial or linear echoendoscope is used for diagnostic EUS. A forward-viewing (FV) echoendoscope may be particularly useful for performing EUS in patients with SAA (Fig. 2). An FV echo-

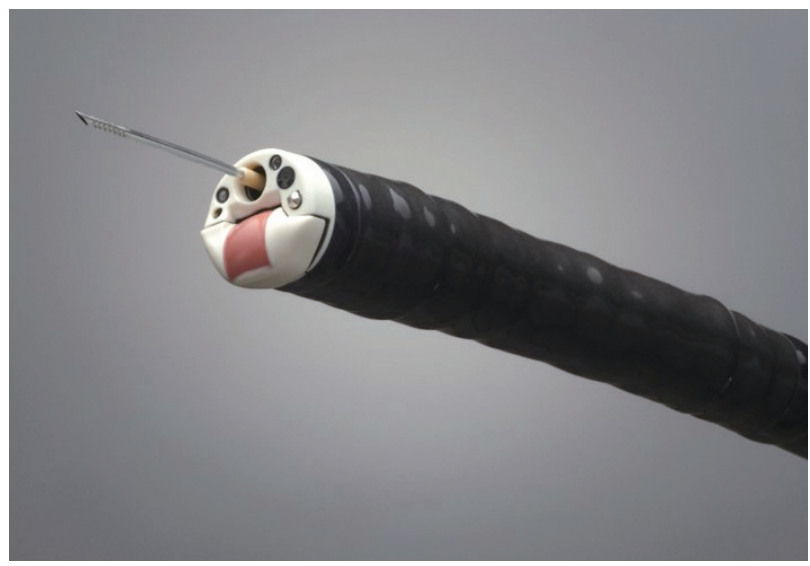

Fig. 2. Forward-viewing (FV) echoendoscope (photo provided by Olympus, Center Valley, PA, USA). endoscope is adapted from the linear echoendoscope by changing the configuration of the tip to incorporate a limited linear EUS view with a standard forward endoscopic view that allows easier advancement through the gastrointestinal (GI) tract compared to traditional oblique-viewing echoendoscopes. Fine-needle aspiration (FNA) or fine-needle biopsy (FNB) may be performed through the FV echoendoscope as with a linear echoendoscope. Other devices may be advanced through the working channel in a straight direction. The FV echoendoscope may be particularly useful in patients who have undergone the Billroth II procedure, while being of little to no benefit in the ever-challenging RYGB anatomy owing to the very long distance that must be traversed to reach the ampulla. $^{15}$

\section{Techniques}

Diagnostic EUS of the pancreatic body and tail are typically performed without difficulty from the remnant stomach in patients with SAA. The real challenge involves imaging the pancreatic head (if present) and neck, as well the bile duct. Diagnostic EUS in patients with Billroth II is best performed using a linear echoendoscope, as it allows a more complete examination of the pancreatic head and bile duct than a radial echoendoscope. ${ }^{16}$ A small series demonstrated that an echoendoscope could be safely advanced to the papilla in 10 out of 11 patients with Billroth II anatomy, although another study reported a success rate of only $66 \%$ for reaching the papilla. ${ }^{16,17}$ Once at the papilla, both radial and linear echoendoscopes visualized the uncinate, superior mesenteric vessels, and periampullary ducts. While the radial echoendoscope only visualized the bile duct and pancreatic head in $50 \%$ of cases, these were well visualized in all cases with the linear echoendoscope. Nonetheless, imaging the pancreatic head may still be challenging due to unfamiliar planes of imaging and reduced ability to torque the echoendoscope in the afferent limb. The pancreatic neck was imaged in $25 \%$ of cases with a radial echoendoscope and $60 \%$ with a linear echoendoscope. ${ }^{16}$ It is important to note that the pancreatic neck is often difficult to visualize in Billroth II anatomy, and usually requires multiple views from the duodenum, jejunum near the GJ anastomosis, and stomach. Fusaroli et al. showed that the use of a FV echoendoscope allowed visualization of the head of the pancreas and the CBD in $100 \%$ of 25 patients, with successful performance of EUS-FNA. ${ }^{15}$

In RYGB, arriving at the ampulla is nearly impossible, with the results of a small study finding conventional EUS of the periampullary area successful in only one out of seven patients with RYGB. In the remaining six patients, the proximal duodenum could not be reached due to difficult intubation of the biliopancreatic limb or long limb length. ${ }^{17}$ With a FV 
echoendoscope, visualization of the pancreatic head and CBD improved slightly to $25 \%$ ( 3 out of 12 patients). Occasionally, the pancreatic neck may be visualized from the proximal Roux limb just distal to the gastrojejunostomy. In contrast to the pancreatic head and neck, the body and tail are usually adequately imaged from the pouch and the proximal Roux limb and are not affected by RYGB anatomy. ${ }^{17,18}$

In patients with post-Whipple anatomy, diagnostic EUS of the remaining pancreatic body and tail can also typically be accomplished from the remaining stomach. Visualization of the biliary tree may prove challenging. The overall success rate (70\% [14 out of 20 patients] in one series) remains better than that achieved in patients with RYGB. Reasons for limited imaging included inability to intubate the afferent limb and obscured views due to intervening bowel gas. ${ }^{17} \mathrm{FV}$ echoendoscopes may enable improved imaging by allowing advancement of the scope down the afferent limb.

\section{THERAPEUTIC EUS}

Endosonography-guided cholangiopancreatography (ESCP) is a procedure in which the bile duct or PD is accessed from the GI tract under real-time ultrasound guidance. ${ }^{19}$ Once the location is confirmed by contrast injection, therapeutic interventions can be performed using ERCP accessories through the echoendoscope working channel. First described by Wiersema et al. in 1996 as a salvage technique for failed ERCP, ESCP is especially useful in patients with SAA, given the difficulty associated with reaching or cannulating the papilla. ESCP may be categorized into biliary versus pancreatic ductal access. The general approaches to drainage are rendezvous, antegrade, and transmural. The access route for EUS-guided biliary drainage (EUS-BD) is extrahepatic (EH) or intrahepatic (IH). In general, preserving the native anatomy and avoiding the creation of new anastomoses is ideal; therefore, the rendezvous or antegrade approaches are preferred. For all therapeutic EUS-guided ductal drainage procedures, a dose of intravenous antibiotics should be administered prior to the intervention to minimize the risk of peritonitis from leakage of enteric or ductal contents at the transmural puncture site; antibiotics may be continued for 3 to 7 days post-procedure at the endoscopist's discretion. All these procedures should be performed with carbon dioxide $\left(\mathrm{CO}_{2}\right)$ insufflation and under general anesthesia.

\section{Tools}

A linear or FV echoendoscope is used for therapeutic EUS procedures. The currently available linear scopes have different working channel sizes ( $2.8 \mathrm{~mm}$ versus 3.7 or $3.8 \mathrm{~mm}$ ). The $2.8 \mathrm{~mm}$ channel allows passage of a 7-Fr stent, while the 3.7 or $3.8 \mathrm{~mm}$ channel accommodates a 10-Fr stent. Typically, a therapeutic linear echoendoscope with the larger working channel is used. In addition, during the rendezvous technique (described below), a therapeutic duodenoscope, colonoscope, or single- or double-balloon enteroscope is required to reach the papilla or anastomosis. If an enteroscope is used, appropriate length accessories including a long guidewire $(600 \mathrm{~cm}$ Tracer Metro ${ }^{\bullet}$ wire, Cook Medical, Bloomington, IN, USA), sphincterotome (Classic Cotton ${ }^{\oplus}$ CannulaTome ${ }^{\oplus}$, Cook Medical), and, if needed, biliary stone extraction balloon $(275 \mathrm{~cm}$ Tri-Ex ${ }^{\oplus}$ balloon, Cook Medical) must be available.

FNA needles are available in three standard sizes $(19,22$, and 25 gauge). For therapeutic intervention, a $19 \mathrm{G}$ or, less commonly, $22 \mathrm{G}$ needle is used to access the biliary or pancreatic system. A 19 G EUS access needle (Cook Medical) may be used that has a special blunt needle tip design that prevents shearing the coating off guidewires (Fig. 3). ${ }^{21}$ If this needle is not used, it is important to avoid withdrawing the wire once it has been advanced beyond the tip of the EUS needle to prevent the needle tip from shearing off the coating. Other ways to reduce the risk of shearing include the following: never withdraw the wire against resistance, straighten out angles before withdrawing the wire, and rotate the wire counterclockwise during withdrawal. Only long $450 \mathrm{~cm}$ guidewires should be used. Guidewires are available in different diameters: $0.018,0.021,0.025,0.032$, and 0.035 inches. It is important to note that a $22 \mathrm{G}$ needle only accepts 0.018 - and 0.021 -inch guidewires, which are more difficult to work with due to their decreased stability for over-the-wire intervention and reduced fluoroscopic visibility. Therefore, once ductal access has been obtained, these wires should be exchanged for larger and stiffer guidewires before interventions are performed. For non-rendezvous procedures, dilation of the enterobiliary
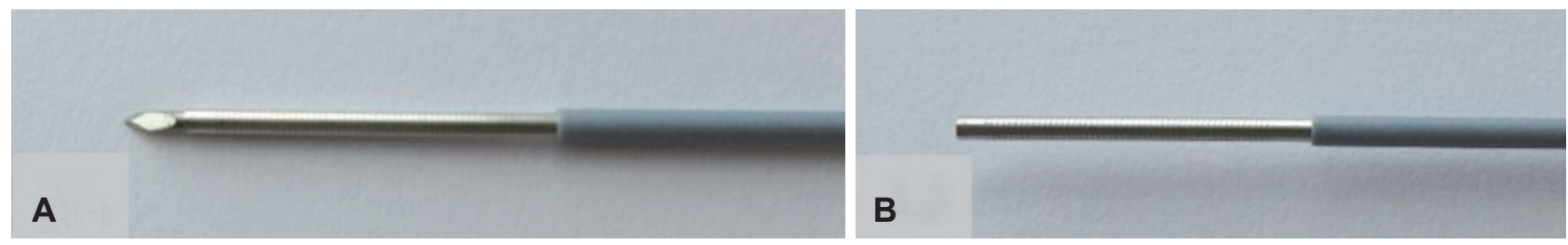

Fig. 3. 19 Gauge endoscopic ultrasound (EUS) access needle (Cook Medical, Bloomington, IN, USA). (A) Beveled stylet. (B) Blunt needle tip. 
or enteropancreatic fistula tract can then be achieved using a bougie (6-7-Fr) or balloon (4-6 $\mathrm{mm}$ ) dilator or a tapered-tip cannula such as a 4-Fr Glo-Tip (Cook Medical) or Proforma (ConMed Endoscopic Technologies, Utica, NY, USA).

Currently available stents include plastic stents, fully covered and partially covered self-expandable metallic stents (SEMS), and lumen apposing metal stents (LAMS). To date, no studies have directly compared the different types of stents. Therefore, the choice of stent is somewhat operator-dependent. In general, a plastic stent is less likely to block drainage of side ducts, but is more prone to clog and harder to exchange than a SEMS. A fully covered SEMS provides a more effective seal against bile leakage and has better long-term patency, but has a higher migration rate and is more likely to block drainage of side ducts. Partially covered stents anchor well, but may cause bile leakage across the open mesh. LAMS are appealing, with potentially decreased migration rates due to the double dumbbell shape, but require an area of at least a $1.0 \mathrm{~cm}$ for deployment. ${ }^{22}$ Of note, none of these stents are currently approved by the Food and Drug Administration (FDA) for this indication. Large studies with long term follow-up are needed to determine the optimal stent for each strategy.

\section{EUS-guided biliary access and intervention}

Biliary ESCP has gained greater acceptance and popularity compared to pancreatic ESCP. This is likely due to its more frequent and pressing indications, in addition to lower risk, compared to pancreatic ESCP. Common indications for biliary ESCP include choledocholithiasis, post-operative leakage, strictures, and cholangitis. While in general the rendezvous and antegrade methods are favored for EUS-BD to preserve normal anatomy, in patients with SAA, a rendezvous proce- dure can be very arduous, as described below. Various algorithms have been proposed to guide EUS-BD. ${ }^{23-25}$ Two recent approaches were remarkably similar in their approach and applicable to SAA. ${ }^{23,25}$ In patients with IH biliary dilation, the IH access route followed by antegrade stent placement or balloon dilation should be performed; however, if this approach fails, transmural hepaticogastrostomy (HG) should be performed. The EH route is available if the IH approach fails, although in SAA, the EH approach is typically not feasible. Because the ampulla or anastomosis is often impossible or difficult to reach in SAA, the rendezvous approach should be attempted only when this area can be readily approached endoscopically (Fig. 4).

\section{EUS-guided rendezvous technique}

The endoscopic rendezvous procedure is derived from the percutaneous technique whereby a guidewire is passed in an anterograde manner across the papilla or surgical anastomosis for subsequent retrograde cannulation of the duct to perform traditional ERCP. ${ }^{26-28}$ In endoscopic rendezvous, instead of percutaneous access under fluoroscopic guidance performed by interventional radiology, the biliary system is accessed under EUS guidance via a transgastric or transduodenal approach. Once biliary access is obtained usually with a 19 G FNA needle, bile is aspirated and contrast injected. The guidewire is then advanced through the bile duct and ampulla or surgical anastomosis and looped inside the small intestine. The echoendoscope is removed while leaving the wire in place, and another scope is advanced beside the wire to the ampulla or anastomosis to re-attempt ERCP using the EUSplaced guidewire to achieve biliary cannulation. The wire is grasped using a snare or biopsy forceps and pulled through

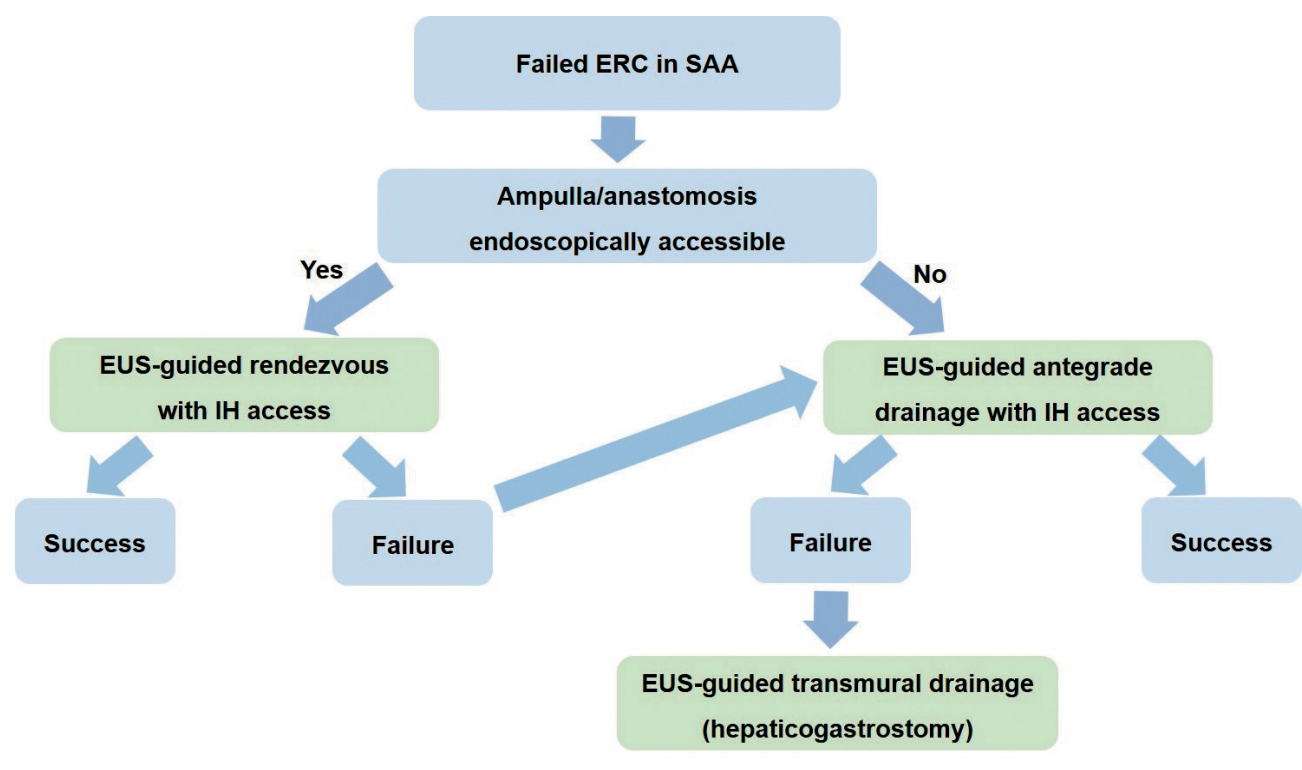

Fig. 4. EUS-guided biliary drainage (EUS-BD) algorithm in surgically altered anatomy (SAA). ERC, endoscopic retrograde cholangiography; EUS, endoscopic ultrasound; $\mathrm{IH}$, intrahepatic. 

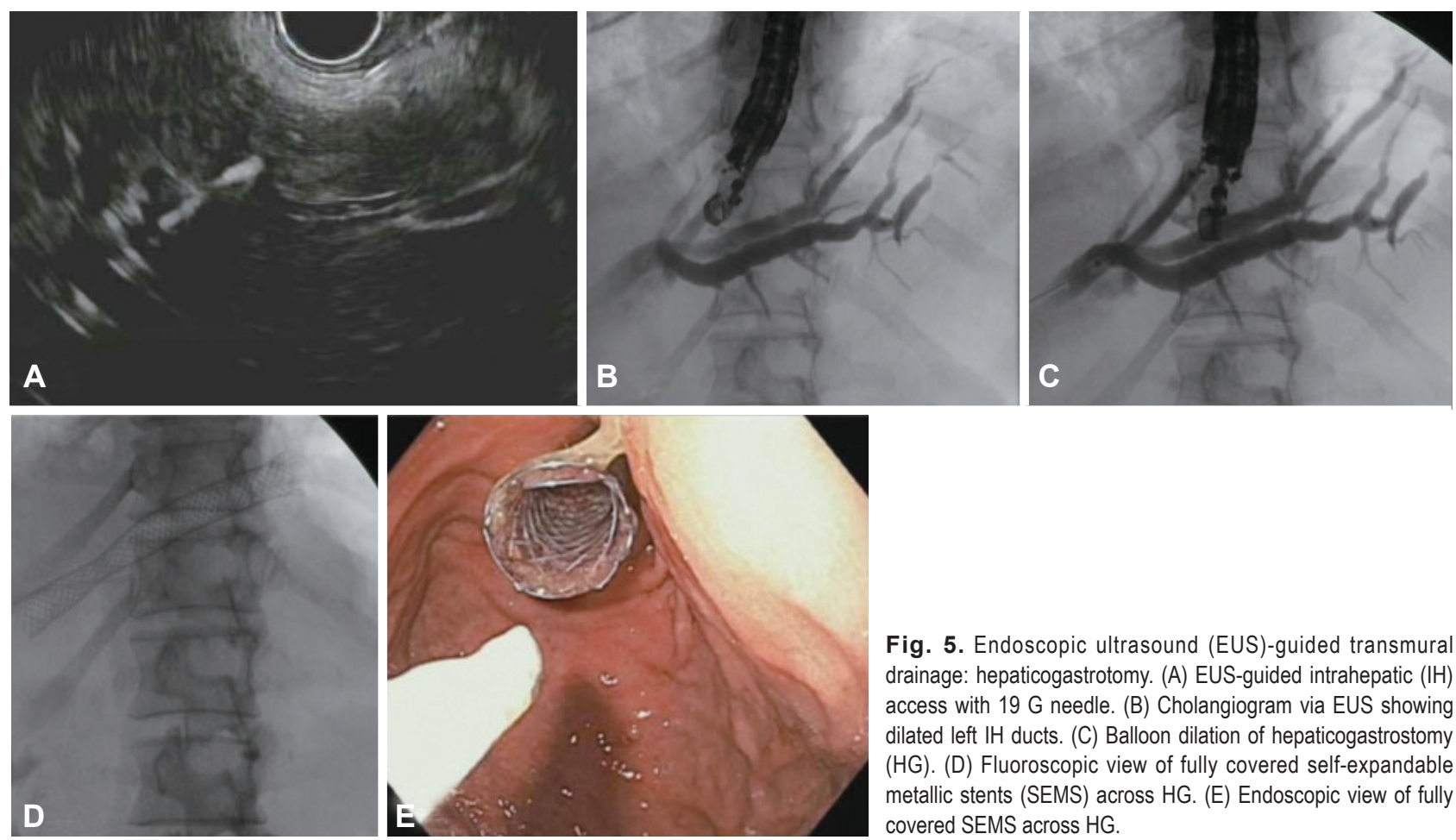

Fig. 5. Endoscopic ultrasound (EUS)-guided transmural drainage: hepaticogastrotomy. (A) EUS-guided intrahepatic $(\mathrm{IH})$ access with $19 \mathrm{G}$ needle. (B) Cholangiogram via EUS showing dilated left IH ducts. (C) Balloon dilation of hepaticogastrostomy (HG). (D) Fluoroscopic view of fully covered self-expandable metallic stents (SEMS) across HG. (E) Endoscopic view of fully covered SEMS across HG.

the working channel until it exits the channel. Two conditions must be met for successful rendezvous: (1) endoscopically accessible papilla (or enterobiliary anastomosis), and (2) successful passage of the guidewire across the papilla into the small bowel.

The rendezvous technique can be divided into an $\mathrm{EH}$ and $\mathrm{IH}$ bile duct approach. In the EH approach, a linear echoendoscope is positioned in the distal antrum, or more commonly, the duodenum, prior to directly accessing the dilated EH biliary tree. This approach is more appealing with a larger duct to target and a shorter distance between the biliary access site and ampulla allowing for better control of the guidewire. In the IH approach, the IH biliary system is visualized by placing a linear echoendoscope in the cardia or the lesser curvature prior to puncturing the dilated left hepatic biliary system transgastrically (Fig. 5A, B). Both EUS and fluoroscopic guidance should be used to direct the needle toward the hilum and $\mathrm{EH}$ bile duct. Advancing the guidewire out through the ampulla or anastomosis can be technically challenging due to the decreased pushability of a wire travelling a long distance. If the access FNA needle is not used, once the wire has been advanced, regardless of whether it is in the correct location, the needle should be removed and replaced with a stiff-tipped cannula to further guide the wire in order to avoid shearing the coating. The approach chosen is anatomy- and operator-dependent. In SAA, the EH approach may be very difficult or impossible, as the antrum and proximal duode- num have in many cases been resected or repositioned a long distance away. An exception to this would be in a patient with RYGB with a gastrogastric fistula that can be exploited to access the defunctionalized stomach and proximal duodenum. Therefore, in most patients with SAA, the IH approach is the access point of choice for EUS-BD.

Unlike in normal anatomy, rendezvous is much more challenging in SAA, as maintaining wire access while making the required change from the echoendoscope to another scope to reach the ampulla or anastomosis will be difficult. This is especially true for patients with RYGB, while Billroth II and Whipple anatomy may lend themselves more readily to rendezvous. Unless a duodenoscope was used to reach the ampulla or anastomosis, performing traditional ERCP remains problematic through FV scopes without elevators, and especially through enteroscopes that require special long accessories. Therefore, the rendezvous technique is likely not the most successful approach to EUS-BD in SAA, particularly in patients with RYGB.

Patients with SAA represent about a fifth to a fourth of biliary rendezvous cases reported in the literature. ${ }^{26,27,29-34}$ The overall technical success rate for the entire cohort ranged from $35 \%$ to $100 \%$. The most common reasons for failure were inability to pass a guidewire across the papilla and failed access to the papilla, especially in patients with SAA. The rate of complications ranged from $12 \%$ to $17 \%$, with complications including abdominal pain, pancreatitis, sepsis, bile leakage 
from the punctured biliary duct, pneumoperitoneum, and subcapsular hematoma.

\section{EUS-guided antegrade drainage}

When the papilla is inaccessible, EUS-guided antegrade drainage should be considered. First performed by Giovannini et al. in 2001, ${ }^{35}$ this procedure involves creating a temporary enterobiliary fistula to access the biliary system and obviate cannulation of the ampulla. The steps through advancing the guidewire into the bile duct are identical to those of a rendezvous procedure. After insertion of the guidewire, dilation of the fistula tract is performed using a bougie ( $4 \mathrm{Fr}$ ) or balloon (4 $\mathrm{mm}$ ) dilator (Fig. 5A-C). Dilation of the tract should be performed to the smallest necessary diameter. Then either a covered or uncovered metal stent is advanced antegrade across the papilla and/or obstruction, or antegrade balloon dilation is performed for choledocholithiasis. Balloon sphincteroplasty is performed in the same manner as during standard ERCP by choosing a balloon diameter comparable to duct size. Following dilation, the same balloon or a biliary stone extraction balloon may be used to push the stones out the ampulla. Throughout the entire procedure, it is important to maintain the original echoendoscope tip position used when the bile duct was accessed with the FNA needle and close apposition of the tip with the intestinal lumen by using both ultrasound and fluoroscopic guidance, especially if using an oblique viewing scope. The main concern with this antegrade approach is bile leak from the temporary enterobiliary fistula. ${ }^{36-38}$ Placement of a second transhepatic stent or a nasobiliary drain following antegrade balloon dilation is optional, and it is unclear whether these additional steps decrease bile leak from the transmural puncture site. As with the rendezvous approach in SAA, EH access is usually not possible.

A few case series reviewed the use of EUS-guided antegrade biliary drainage in patients with both normal anatomy and SAA. ${ }^{36,37,39,40}$ In these small studies, the technical success rate ranged from $67 \%$ to $100 \%$ for the entire cohort, with a clinical success rate of approximately $78 \%$. Complications occurred in about $5 \%$ of cases and included abdominal pain, mild pancreatitis, and hepatic subcapsular hematoma. ${ }^{36,38,41-43}$

\section{EUS-guided transmural drainage}

If the wire cannot be advanced across the obstruction and/ or papilla, transmural drainage should be performed. In this technique, once biliary access is obtained, a stent is placed above the obstruction across the bowel wall (Fig. 5). This may be achieved with either a hepaticogastric or choledochoduodenal approach. For choledochoduodenostomy (CD), allowing the guidewire to advance into the proximal duct toward the hilum usually leads to easier advancement of the stent across the duodenal wall. In patients with duodenal obstruction, HG may be favored, as a study found increased patency and decreased complications with this procedure compared to $\mathrm{CD} .{ }^{44}$ In SAA, CD is likely impossible in the same way that $\mathrm{EH}$ access is in these patients. HG may also be difficult if there is limited space on the intestinal side to deploy a fully covered SEMS. Uncovered metal stents should not be used transmurally to avoid bile leak and peritonitis. Advantages of covered metal stents over plastic stents include possible decreased cholangitis and increased stent patency, while disadvantages include potential increased migration and occlusion of secondary ducts. Placing a double pigtail stent through the covered metal stent may decrease migration. For malignancies, fully covered SEMS 6 or $8 \mathrm{~cm}$ long are favored. Further study is required to determine the optimal stent choice in different situations.

Data regarding EUS-guided transmural drainage are promising, showing a technical success rate of approximately $90 \%{ }^{30,32,33,40,45-50}$ Patients with post-surgical anatomy constituted about a third to a half of the cases in these studies. The complication rate, however, was reported to be as high as $22 \%$, with complications including bile leakage, pneumoperitoneum, cholangitis, biloma, ileus, and stent occlusion.

\section{Comparison of approaches}

A few studies have compared EUS-BD to traditional drainage approaches. EUS-BD for distal biliary strictures using $\mathrm{CD}$ or antegrade drainage appeared comparable to ERCP in technical and clinical success rates, procedural time, and adverse event rate in a multicenter, retrospective study that included more than 200 patients, among whom only 5 patients had SAA. ${ }^{51}$ Similarly, a randomized trial including 32 patients (only 1 with SAA) with malignant distal biliary obstruction demonstrated no difference in technical and clinical success, quality of life, and survival among patients who underwent EUS-guided CD versus surgical bypass after failed ERCP. ${ }^{52}$ When compared to percutaneous biliary drainage, EUS-BD had equivalent clinical success, stent patency, and survival, and was associated with decreased adverse events, rate of reinterventions, and total hospital charges following failed ERCP in 73 patients, among whom none were clearly identified to have SAA. ${ }^{53}$ The technical success rate of EUS-BD was inferior $(86 \%)$ to that of percutaneous drainage (100\%). Another retrospective study examining malignant biliary obstruction and failed ERCP in 51 patients (9 with SAA) showed that EUS-BD via antegrade or transmural drainage had a higher success rate and lower complication rate compared to percutaneous drainage, although a $46 \%$ success rate by interventional radiology is far lower than rates reported in other studies. ${ }^{54}$ A small randomized study of 25 patients (1 with SAA) with 


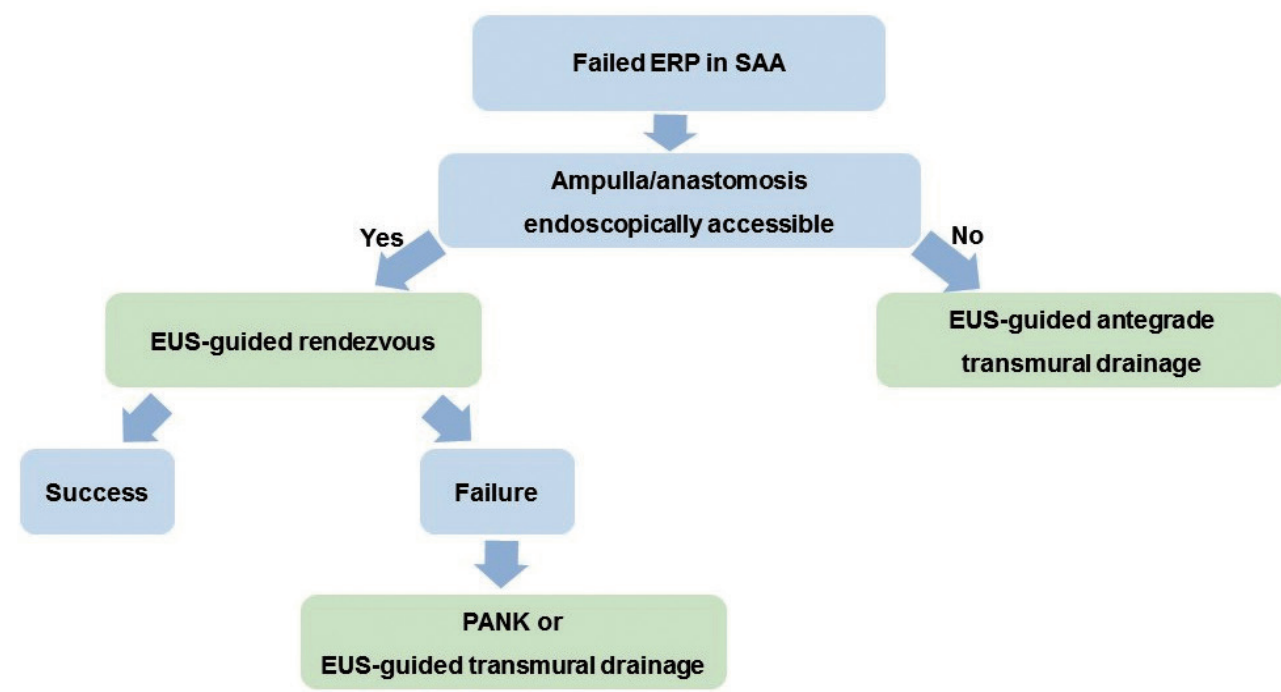

Fig. 6. Endoscopic ultrasound (EUS)-guided pancreatic drainage algorithm in surgically altered anatomy (SAA). ERP, endoscopic retrograde pancreatography; PANK, pancreatic antegrade needle-knife. failed ERCP demonstrated similar success and complication rates between the EUS-CD and percutaneous drainage arms. ${ }^{55}$ Whether these results would hold true in patients with SAA will require further study.

\section{EUS-guided pancreatic duct access and intervention}

In 1995, Harada et al. first reported the use of EUS-guided pancreatography to diagnose a pancreatic stone in a patient with Whipple anatomy. ${ }^{56}$ Since then, the procedure has drastically evolved and is currently used for both diagnostic and therapeutic indications, although predominantly for the latter, especially in patients with SAA. Common indications include stenosis of the PJ with or without pancreatic fistula (seen in $30 \%$ to $50 \%$ of patients who have undergone the Whipple procedure), ${ }^{57-59} \mathrm{PD}$ stricture or stones in chronic pancreatitis, main pancreatic duct (MPD) disruption, and failed endoscopic retrograde pancreatography (ERP). Overall, EUS-guided pancreatic duct drainage (EUS-PD) has been associated with lower success (69\%) and higher complication rates (42.9\%) than EUS-BD, although recent multicenter international retrospective studies suggested improved rates of success $(>90 \%$ technical and $81 \%-88 \%$ clinical success). ${ }^{60,61}$ Of note, $63 \%$ of the patients in these recent studies had SAA.

Diagnostic EUS may be effective if the ampulla or PJ anastomosis cannot be identified endoscopically. EUS-guided injection of the PD using a combination of $1 \%$ methylene blue and contrast (1:4 mixture) through a 22 or $25 \mathrm{G}$ needle may help safely identify the papilla or anastomosis. ${ }^{62}$ If contrast exits into the intestine, traditional ERP can be pursued. If contrast does not enter the small bowel, an EUS-guided rendezvous or antegrade approach should be pursued. The challenge with this approach is the need to change scopes multiple times. In Fig. 6, we present an algorithm for the approach to EUS-PD based on the principle of preserving normal anatomy.

\section{EUS-guided rendezvous technique}

In the EUS-guided rendezvous technique for the $\mathrm{PD}$, the principles are similar to those for the bile duct. The MPD is accessed via a transgastric approach in SAA using a 19 or 22 $\mathrm{G}$ needle with contrast injection. A guidewire is traversed across the papilla or anastomosis and coiled in the small intestine followed by removal of the echoendoscope and advancement of a standard therapeutic duodenoscope, colonoscope, or balloon enteroscope alongside the wire to the papilla to perform retrograde intervention (Fig. 7). Similar to the biliary rendezvous, the pancreatic rendezvous procedure requires that: (1) the papilla is accessible endoscopically, and (2) the guidewire can be successfully passed across the papilla or anastomosis into the small bowel.

Both accessing the MPD and advancing the guidewire out the papilla or anastomosis can prove challenging. Obstacles to entering the MPD include a long distance between the stomach wall and duct, fibrotic pancreatic parenchyma, and nondilated MPD. A $22 \mathrm{G}$ needle is favored in the latter two situations. Selecting the optimal angle (avoid perpendicular entry) to access the MPD with the least distance possible between the pancreas and gastric wall is critical. Using the appropriate guidewire may also be crucial for successful advancement into the intestine, and the needle should be changed to a tapered cannula for maneuvering the wire. The 0.025 in VisiGlide (Olympus Medical, Center Valley, PA, USA) and hydrophilic guidewires as well as angled-tip wires may be particularly useful.

A few case series described EUS-guided pancreatic rendezvous. $^{26,62-71}$ In these series, approximately $40 \%$ of patients (30 of 74) had SAA. The technical success rate ranged from $25 \%$ to $100 \%$ for the entire cohort (both patients with 

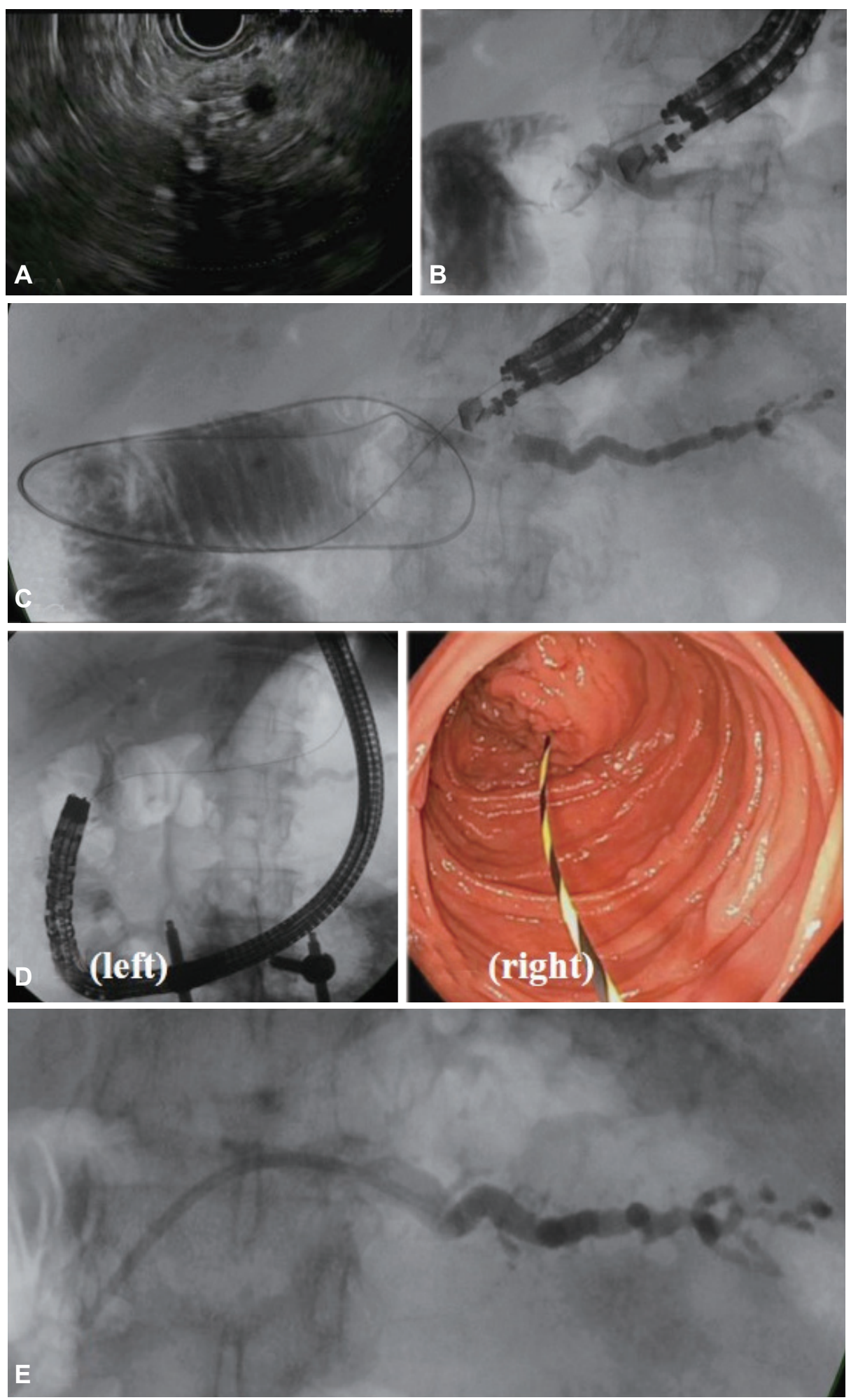

Fig. 7. Endoscopic ultrasound (EUS)-guided pancreatic rendezvous in post-Whipple patient with anastomotic stricture. (A) EUS of dilated main pancreatic duct (MPD). (B) EUS-guided access to dilated main PD with $19 \mathrm{G}$ needle. (C) Long 0.035 -inch guidewire advanced through stenosed pancreaticojejunostomy (PJ) and coiled in jejunum. (D) Echoendoscope removed, leaving guidewire in place. Colonoscope advanced alongside guidewire and distal end captured with forceps to complete rendezvous. Left: fluoroscopic and right: endoscopic view. (E) Pancreatic stent placed across anastomosis via traditional endoscopic retrograde cholangiopancreatography (ERCP) using colonoscope. Courtesy of Dr. Christopher Thompson, Brigham and Women's Hospital.

normal anatomy and patients with SAA combined), with clinical success rates of $100 \%$ in those who successfully underwent the procedure. The mean follow-up period was 1 to 25.2 months. From $0 \%$ to $42.9 \%$ of the entire cohort required repeat endoscopic or surgical intervention. Procedures in all
SAA cases were performed transgastrically, with a $19 \mathrm{G}$ needle in most cases. The reasons for technical failure included inability to obtain an EUS-guided pancreatogram and advance the wire downstream in the MPD. Adverse event rates for the entire cohort ranged from $0 \%$ to $25 \%$ and included 

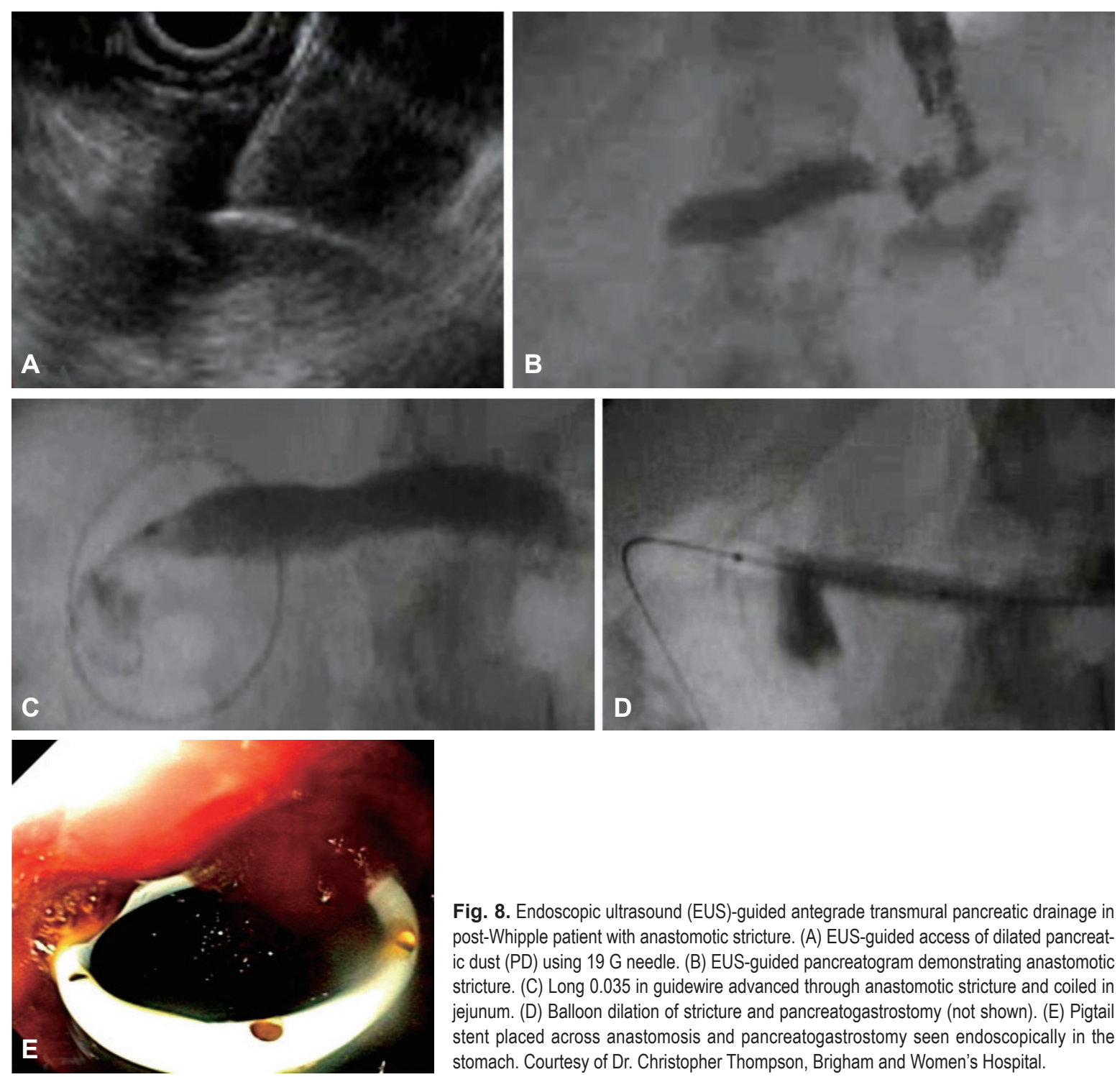

Fig. 8. Endoscopic ultrasound (EUS)-guided antegrade transmural pancreatic drainage in post-Whipple patient with anastomotic stricture. (A) EUS-guided access of dilated pancreatic dust (PD) using $19 \mathrm{G}$ needle. (B) EUS-guided pancreatogram demonstrating anastomotic stricture. (C) Long 0.035 in guidewire advanced through anastomotic stricture and coiled in jejunum. (D) Balloon dilation of stricture and pancreatogastrostomy (not shown). (E) Pigtail stent placed across anastomosis and pancreatogastrostomy seen endoscopically in the stomach. Courtesy of Dr. Christopher Thompson, Brigham and Women's Hospital.

pancreatitis, peripancreatic abscess, and pancreatic juice leakage.

\section{EUS-guided antegrade drainage}

When the papilla or anastomosis is inaccessible or unable to be traversed with the guidewire, EUS-guided antegrade drainage should be considered. In this procedure, the steps through advancing the guidewire into the MPD are identical to those for the rendezvous procedure. Then the needle track is dilated and a stent placed transmurally with the proximal end in the stomach and the distal end either within the MPD, crossing the papilla, or anastomosis. If possible, transpapillary or transanastomotic drainage is preferable as this follows physiologic drainage (Fig. 8).

Both dilation and stent placement can prove extremely challenging. Keys to successful dilation include the following: choose a dilator catheter or balloon with a diameter comparable to the stent, select dilators with stiff tapered tips (for example, Hurricane ${ }^{\mathrm{Tw}} \mathrm{RX}$ Biliary Dilation Balloon, Boston Scientific, Marlborough, MA, USA), and maintain the original scope tip position used when the needle was advanced into the MPD using both ultrasonographic and fluoroscopic imaging. Use of diathermic catheters such as needle knives is controversial, and many experts recommend using them only as a last resort and with very short bursts of cautery.

Despite successful dilation, stent placement may be arduous. Traditionally a long 5- or 7-Fr plastic stent has been used. Double pigtail stents may be less prone to migration than straight stents. ${ }^{57}$ Pancreatic stents usually have multiple side holes to prevent blockage of side branches, but this may facilitate leakage of pancreatic fluid when stenting across the stomach wall into the pancreas. A new 7-Fr $20 \mathrm{~cm}$ long 
pancreatic stent with two flanges at both ends, a tapered distal end with a single side hole, and a proximal single pigtail (Gadelius Medical Co., Tokyo, Japan) was introduced with promising initial results. ${ }^{72}$ Recently a modified 6 or $8 \mathrm{~mm}$ diameter fully covered 6-10 cm long SEMS with blunt ends and 4 anti-migration flaps at both ends (M.I. Tech, Seoul, Korea) also demonstrated favorable preliminary findings without evidence of blocked side branches. ${ }^{73}$ Theoretical advantages of covered metal stents compared to plastic stents include prolonged patency and decreased pancreatic fluid leakage. Uncovered SEMs should be avoided as they may lead to pancreatic juice leakage between the stomach and pancreas. Clearly, further large-scale prospective studies are necessary to determine the ideal stent type.

To date, there have been about 30 cases of patients with SAA who underwent EUS-guided antegrade PD stenting reported in the literature. ${ }^{66,74-76}$ All procedures were performed via a transgastric approach. Most endosonographers used $19 \mathrm{G}$ needles for the first puncture and a dilating catheter or balloon for tract dilation. The technical success rate for the entire cohort was greater than $70 \%$. The reported rate of adverse events ranged from $0 \%$ to $67 \%$ and included abdominal pain, pancreatitis, bleeding, perforation, shaving of the guidewire coating, peripancreatic abscess, pseudocyst, and stent migration. Stent dysfunction in over $50 \%$ of patients is the predominant concern during long-term follow-up. ${ }^{77,78}$ A recent international multicenter retrospective study of 66 patients post-Whipple compared 40 EUS-PD procedures to 35 enteroscopy-assisted ERPs. ${ }^{61}$ Both technical and clinical success was superior with the EUS approach (88\%-93\% vs. $20 \%-23 \%$ ), although complications were also greater (35\% vs. $3 \%)$. All complications were mild or moderate, with $81 \%$ of reported complications classified as abdominal pain requiring hospitalization. Similar numbers of patients underwent antegrade or transluminal stenting while a minority (7.5\%) underwent rendezvous.

\section{Pancreatic antegrade needle-knife}

When a guidewire cannot be advanced through the papilla or anastomosis, the pancreatic antegrade needle-knife (PANK) procedure may be considered as a modification to the rendezvous approach. In 2010, Thompson reported this technique for treatment of post-Whipple patients with symptomatic stenosis of the PJ anastomosis in cases when the guidewire fails to advance through the anastomosis. ${ }^{76}$ After accessing the MPD with a wire and dilating the tract, a wire-guided needle knife is advanced to the anastomosis until indentation of the air-filled jejunum is visualized fluoroscopically while pushing the needle knife forward. Antegrade needle-knife PJ is performed under fluoroscopy followed by advancement of the wire and needle knife into the jejunum, balloon dilation of the anastomosis, and long plastic stent placement extending from the jejunum into the stomach. Keys to this procedure include having the ability to access the anastomosis endoscopically; distending the afferent limb with $\mathrm{CO}_{2}$ and, potentially, contrast; and carefully visualizing the needle knife fluoroscopically before and during application of cautery.

In this case series, all 3 patients who previously failed EUS-guided rendezvous and antegrade access of the PD successfully underwent the PANK procedure with resolution of their pain at the time of stent removal. One out of 3 patients (33\%) had mild pancreatitis that resolved with conservative management.

\section{Special circumstances}

\section{EUS-directed transgastric ERCP}

Performing ERCP in patients with RYGB anatomy is particularly challenging due to the long limbs that need to be traversed and the angle at the JJ anastomosis. In 1998, Baron et al. first described the use of surgical gastrostomy to access the remnant stomach of patients with RYGB followed by ERCP via the gastrostomy 2 weeks later. ${ }^{79}$ Since then, the technique has undergone modifications including replacement of surgical gastrostomy with EUS-assisted percutaneous gastric remnant access. Also known as EUS-directed transgastric ERCP (EDGE), the procedure may be classified as external or internal EDGE based on the approach used to access the remnant stomach.

\section{External EUS-directed transgastric ERCP}

In 2014, Thompson et al. ${ }^{80}$ reported the use of EUS-assisted percutaneous gastric access for single-session ERCP. In this technique, EUS is used to access the remnant stomach from the pouch using a $22 \mathrm{G}$ needle (Fig. 9). Contrast is injected, and the remnant stomach is distended with carbon dioxide. Under fluoroscopic guidance, a T-tag needle is advanced percutaneously into the remnant stomach with a total of 4 T-tags used to affix the remnant stomach to the abdominal wall. A needle and guidewire are then inserted percutaneously into the remnant stomach. A fully covered esophageal stent is placed over the wire and balloon dilated to $18 \mathrm{~mm}$. ERCP is then performed by passing the duodenoscope through the stent. At the end of the procedure, the stent is exchanged for a gastrostomy tube, which is later removed. ${ }^{80}$

Kahaleh and colleagues reported a two-session external EDGE technique. In the first stage, a percutaneous endoscopic gastrostomy (PEG) tube is placed into the remnant stomach under EUS and fluoroscopic guidance. After ac- 

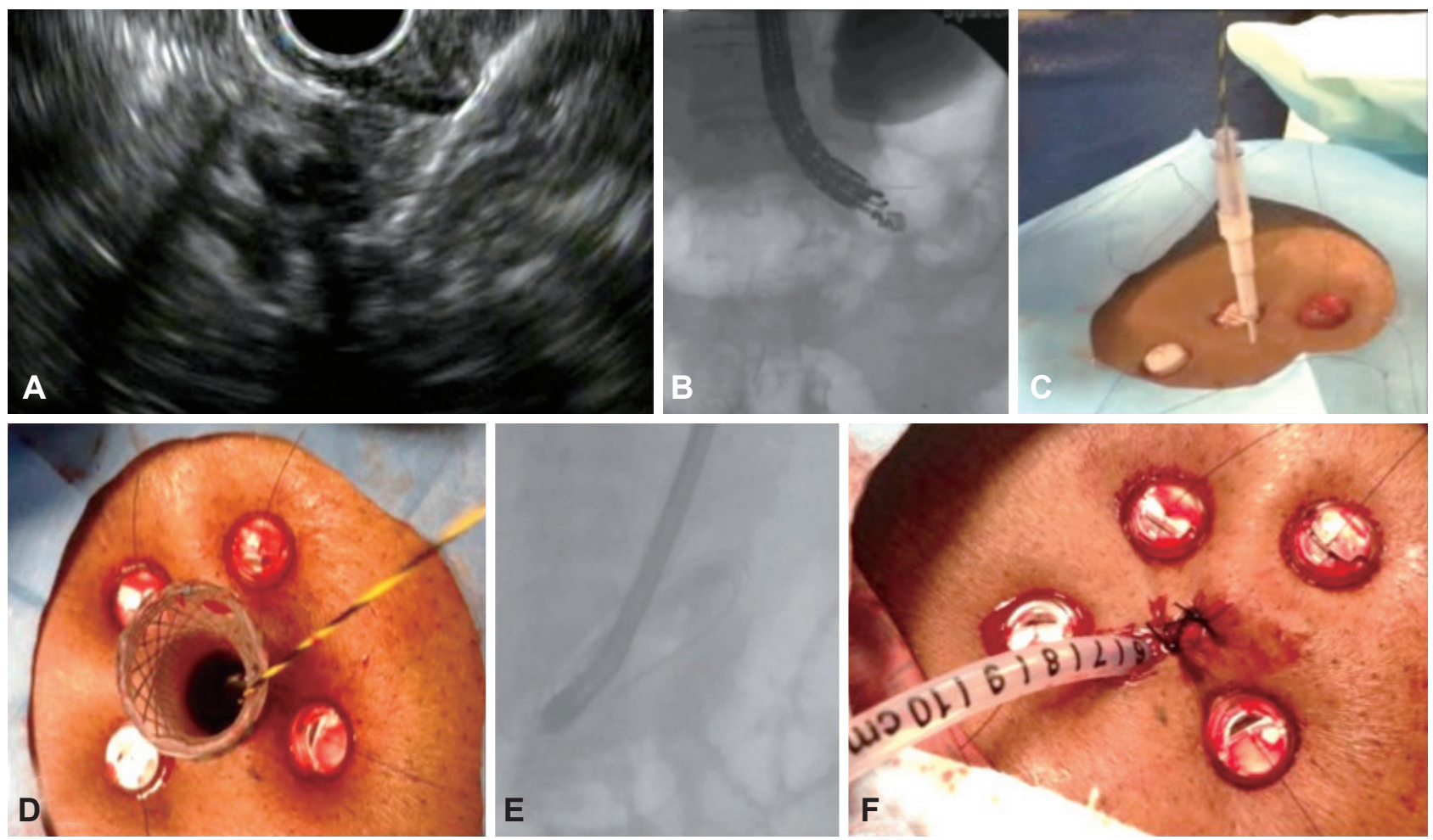

Fig. 9. External endoscopic ultrasound (EUS)-directed transgastric endoscopic retrograde cholangiopancreatography (ERCP). (A) EUS-guided access of the remnant stomach using $22 \mathrm{G}$ needle. (B) Contrast injection into the remnant stomach. (C) Percutaneous access into the remnant stomach using four T-tags, introducer needle, and guidewire. (D) Fully covered esophageal stent advanced over wire and balloon dilated to $18 \mathrm{~mm}$. (E) Duodenoscope inserted through the stent to perform ERCP. (F) Stent exchanged for a gastrostomy tube. Courtesy of Dr. Christopher Thompson, Brigham and Women's Hospital.

cessing the remnant stomach from the pouch with a $19 \mathrm{G}$ FNA needle and distending the pouch with air and water, a guidewire is coiled in the remnant stomach. A 22 G Chiba needle is advanced into it followed by contrast injection, and then an $18 \mathrm{G}$ Chiba needle is placed alongside this in order to advance a stiff guidewire into the remnant stomach over which a 16 Fr PEG tube is placed. During the second stage, performed 3 to 9 days later, after removal of the PEG over a guidewire, the steps are analogous to those of the Thompson paper, with T-tags placed to secure the remnant stomach to the abdominal wall followed by dilation of the fistula tract, placement of a fully covered $23 \times 125 \mathrm{~mm}$ esophageal stent, performance of ERCP through the stent, and exchange of the esophageal stent for a PEG tube. ${ }^{81}$ In this case series, both EUS-guided PEG placement and ERCP were successfully performed in all six cases (100\%). Two patients experienced local infection at the PEG site that was managed with oral antibiotics.

\section{Internal EUS-directed transgastric ERCP}

During internal EDGE, instead of accessing the remnant stomach percutaneously, a LAMS is used to create a gastrogastric fistula between the gastric remnant and pouch. ${ }^{82}$ Under EUS guidance, a $19 \mathrm{G}$ needle enters the remnant stomach, a guidewire is advanced through the needle, the fistula is dilated to $4 \mathrm{~mm}$ over the wire, a LAMS is placed, the stent is dilated to $18 \mathrm{~mm}$, and a duodenoscope is passed through the LAMS to perform ERCP. A few weeks later, the stent is removed and the gastrogastric fistula is repaired with endoscopic suturing. While internal EDGE may be considered less invasive compared to external EDGE, creation of a gastrogastric fistula that may be difficult to close creates other potential problems that must be addressed in longterm large-scale studies before this technique can be broadly adopted.

\section{CONCLUSION}

EUS has become a powerful diagnostic and therapeutic tool in management of biliopancreatic diseases in patients with SAA. It has matured over the past decade and is increasingly replacing percutaneous and surgical approaches. Data regarding the feasibility, safety, and long-term efficacy of these EUS-guided techniques specifically in the SAA population are needed. Additionally, optimal accessories including needles, guidewires, dilators, and stents for each technique remain to be determined. It is expected that the use 
of EUS-based approaches to manage patients with SAA will continue to grow. Experienced endoscopists with training in both EUS and ERCP should therefore become familiar and experienced with these techniques in order to effectively care for this challenging patient population.

\section{Conflicts of Interest}

The authors have no financial conflicts of interest.

\section{REFERENCES}

1. Kethu SR, Adler DG, Conway JD, et al. ERCP cannulation and sphincterotomy devices. Gastrointest Endosc 2010;71:435-445.

2. Enestvedt BK, Kothari S, Pannala R, et al. Devices and techniques for ERCP in the surgically altered GI tract. Gastrointest Endosc 2016;83:1061-1075.

3. Moreels TG. Endoscopic retrograde cholangiopancreatography in patients with altered anatomy: How to deal with the challenges? World J Gastrointest Endosc 2014;6:345-351.

4. Al-Lehibi AH, Kumar N, Sayuk GS, et al. Success Rates for Endoscopic Retrograde Cholangiopancreatography (ERCP) in Patients With Altered Anatomy From Prior Surgical Intervention. Gastrointest Endosc 2010;71:AB228.

5. Skinner M, Popa D, Neumann H, Wilcox CM, Mönkemüller K. ERCP with the overtube-assisted enteroscopy technique: a systematic review. Endoscopy 2014;46:560-572.

6. Feitoza AB, Baron TH. Endoscopy and ERCP in the setting of previous upper GI tract surgery. Part I: reconstruction without alteration of pancreaticobiliary anatomy. Gastrointest Endosc 2001;54:743-749.

7. Feitoza AB, Baron TH. Endoscopy and ERCP in the setting of previous upper GI tract surgery. Part II: postsurgical anatomy with alteration of the pancreaticobiliary tree. Gastrointest Endosc 2002;55:75-79.

8. Bilroth T. Offenes Schreiben an Herrn Dr. L. Wittelshöfer. Wien Med Wochenschr 1881;31:161-165.

9. Mason EE, Ito C. Gastric bypass in obesity. Surg Clin North Am 1967;47:1345-1351.

10. Ponce J, Nguyen NT, Hutter M, Sudan R, Morton JM. American Society for Metabolic and Bariatric Surgery estimation of bariatric surgery procedures in the United States, 2011-2014. Surg Obes Relat Dis 2015;11:1199-1200.

11. Cameron JL. Atlas of surgery. vol 2. St. Louis: Mosby; 1994.

12. Jones DB, Maithel SK, Schneider BE. Atlas of minimally invasive surgery. Woodbury, CT: Cine-Med; 2006.

13. Sauve L. Des pancréatectomies et spécialement de la pancréatectomie céphalique. Rev chir 1908;37:113-152, 335-385.

14. Whipple AO, Parsons WB, Mullins CR. TREATMENT OF CARCINOMA OF THE AMPULLA OF VATER. Ann Surg 1935;102:763-779.

15. Fusaroli P, Serrani M, Lisotti A, D’Ercole MC, Ceroni L, Caletti G. Performance of the forward-view echoendoscope for pancreaticobiliary examination in patients with status post-upper gastrointestinal surgery. Endosc Ultrasound 2015;4:336-341.

16. Lee JH, Topazian M. Pancreatic endosonography after Billroth II gastrectomy. Endoscopy 2004;36:972-975.

17. Wilson JA, Hoffman B, Hawes RH, Romagnuolo J. EUS in patients with surgically altered upper GI anatomy. Gastrointest Endosc 2010;72:947953.

18. Sanders M, McGrath K. Endoscopic Ultrasound in the Patient with Difficult Anatomy. Tech Gastrointest Endosc 2007;9:84-89.

19. Kahaleh M, Artifon EL, Perez-Miranda M, et al. Endoscopic ultrasonography guided biliary drainage: summary of consortium meeting, May 7th, 2011, Chicago. World J Gastroenterol 2013;19:1372-1379.

20. Wiersema MJ, Sandusky D, Carr R, Wiersema LM, Erdel WC, Frederick
PK. Endosonography-guided cholangiopancreatography. Gastrointest Endosc 1996;43:102-106.

21. Giovannini M, Bories E, Tellez F. EUS-Guided Bilio-Pancreatic Drainage. In: Lee LS, ed. ERCP and EUS: A Case-Based Approach. New York (NY): Springer; 2015. p. 575-588.

22. Kunda R, Pérez-Miranda M, Will U, et al. EUS-guided choledochoduodenostomy for malignant distal biliary obstruction using a lumen-apposing fully covered metal stent after failed ERCP. Surg Endosc 2016;30:5002-5008.

23. Tyberg A, Desai AP, Kumta NA, et al. EUS-guided biliary drainage after failed ERCP: a novel algorithm individualized based on patient anatomy. Gastrointest Endosc 2016 May 26 [Epub]. http://dx.doi.org/10.1016/ j.gie.2016.05.035.

24. Weilert F. Prospective evaluation of simplified algorithm for EUS-guided intra-hepatic biliary access and anterograde interventions for failed ERCP. Surg Endosc 2014;28:3193-3199.

25. Khashab MA, Valeshabad AK, Modayil R, et al. EUS-guided biliary drainage by using a standardized approach for malignant biliary obstruction: rendezvous versus direct transluminal techniques (with videos). Gastrointest Endosc 2013;78:734-741.

26. Mallery S, Matlock J, Freeman ML. EUS-guided rendezvous drainage of obstructed biliary and pancreatic ducts: Report of 6 cases. Gastrointest Endosc 2004;59:100-107.

27. Kahaleh M, Yoshida C, Kane L, Yeaton P. Interventional EUS cholangiography: A report of five cases. Gastrointest Endosc 2004;60:138-142.

28. Gupta K, Mallery S, Hunter D, Freeman ML. Endoscopic ultrasound and percutaneous access for endoscopic biliary and pancreatic drainage after initially failed ERCP. Rev Gastroenterol Disord 2007;7:22-37.

29. Kahaleh M, Wang P, Shami VM, Tokar J, Yeaton P. EUS-guided transhepatic cholangiography: report of 6 cases. Gastrointest Endosc 2005;61:307-313.

30. Brauer BC, Chen YK, Fukami N, Shah RJ. Single-operator EUS-guided cholangiopancreatography for difficult pancreaticobiliary access (with video). Gastrointest Endosc 2009;70:471-479.

31. Tarantino I, Barresi L, Repici A, Traina M. EUS-guided biliary drainage: a case series. Endoscopy 2008;40:336-339.

32. Maranki J, Hernandez AJ, Arslan B, et al. Interventional endoscopic ultrasound-guided cholangiography: long-term experience of an emerging alternative to percutaneous transhepatic cholangiography. Endoscopy 2009;41:532-538.

33. Shah JN, Marson F, Weilert F, et al. Single-operator, single-session EUS-guided anterograde cholangiopancreatography in failed ERCP or inaccessible papilla. Gastrointest Endosc 2012;75:56-64.

34. Dhir V, Bhandari S, Bapat M, Maydeo A. Comparison of EUS-guided rendezvous and precut papillotomy techniques for biliary access (with videos). Gastrointest Endosc 2012;75:354-359.

35. Giovannini M, Moutardier V, Pesenti C, Bories E, Lelong B, Delpero JR. Endoscopic ultrasound-guided bilioduodenal anastomosis: a new technique for biliary drainage. Endoscopy 2001;33:898-900.

36. Weilert F, Binmoeller KF, Marson F, Bhat Y, Shah JN. Endoscopic ultrasound-guided anterograde treatment of biliary stones following gastric bypass. Endoscopy 2011;43:1105-1108.

37. Park DH, Jang JW, Lee SS, Seo DW, Lee SK, Kim MH. EUS-guided transhepatic antegrade balloon dilation for benign bilioenteric anastomotic strictures in a patient with hepaticojejunostomy. Gastrointest Endosc 2012;75:692-693.

38. Iwashita T, Yasuda I, Doi S, et al. Endoscopic ultrasound-guided antegrade treatments for biliary disorders in patients with surgically altered anatomy. Dig Dis Sci 2013;58:2417-2422.

39. Nguyen-Tang T, Binmoeller KF, Sanchez-Yague A, Shah JN. Endoscopic ultrasound (EUS)-guided transhepatic anterograde self-expandable metal stent (SEMS) placement across malignant biliary obstruction. Endoscopy 2010;42:232-236.

40. Puspok A, Lomoschitz F, Dejaco C, Hejna M, Sautner T, Gangl A. Endoscopic ultrasound guided therapy of benign and malignant biliary 
obstruction: a case series. Am J Gastroenterol 2005;100:1743-1747.

41. Iwashita T, Nakai $Y$, Hara K, Isayama H, Itoi T, Park do H. Endoscopic ultrasound-guided antegrade treatment of bile duct stone in patients with surgically altered anatomy: a multicenter retrospective cohort study. J Hepatobiliary Pancreat Sci 2016;23:227-233.

42. Itoi T, Sofuni A, Tsuchiya T, Ijima M, Iwashita T. Endoscopic ultrasonography-guided transhepatic antegrade stone removal in patients with surgically altered anatomy: case series and technical review (with videos). J Hepatobiliary Pancreat Sci 2014;21:E86-E93.

43. Sansak I, Itoi T, Moriyasu F. Endoscopic ultrasonography-guided transhepatic antegrade stone removal in a patient with Roux-en-Y anastomosis (with video). J Hepatobiliary Pancreat Sci 2014;21:719-720.

44. Ogura T, Chiba Y, Masuda D, et al. Comparison of the clinical impact of endoscopic ultrasound-guided choledochoduodenostomy and hepaticogastrostomy for bile duct obstruction with duodenal obstruction. Endoscopy 2016;48:156-163.

45. Burmester E, Niehaus J, Leineweber T, Huetteroth T. EUS-cholangio-drainage of the bile duct: report of 4 cases. Gastrointest Endosc 2003;57:246-251.

46. Giovannini M, Dotti M, Bories E, et al. Hepaticogastrostomy by echo-endoscopy as a palliative treatment in a patient with metastatic biliary obstruction. Endoscopy 2003;35:1076-1078.

47. Kahaleh M, Hernandez AJ, Tokar J, Adams RB, Shami VM, Yeaton P. Interventional EUS-guided cholangiography: evaluation of a technique in evolution. Gastrointest Endosc 2006;64:52-59.

48. Artifon EL, Chaves DM, Ishioka S, Souza TF, Matuguma SE, Sakai P. Echoguided hepatico-gastrostomy: a case report. Clinics (Sao Paulo) 2007;62:799-802.

49. Will U, Thieme A, Fueldner F, Gerlach R, Wanzar I, Meyer F. Treatment of biliary obstruction in selected patients by endoscopic ultrasonography (EUS)-guided transluminal biliary drainage. Endoscopy 2007;39:292-295.

50. Bories E, Pesenti C, Caillol F, Lopes C, Giovannini M. Transgastric endoscopic ultrasonography-guided biliary drainage: results of a pilot study. Endoscopy 2007;39:287-291.

51. Dhir V, Itoi T, Khashab MA, et al. Multicenter comparative evaluation of endoscopic placement of expandable metal stents for malignant distal common bile duct obstruction by ERCP or EUS-guided approach. Gastrointest Endosc 2015;81:913-923.

52. Artifon EL, Loureiro JF, Baron TH, Fernandes K, Kahaleh M, Marson FP. Surgery or EUS-guided choledochoduodenostomy for malignant distal biliary obstruction after ERCP failure. Endosc Ultrasound 2015;4:235-243.

53. Khashab MA, Valeshabad AK, Afghani E, et al. A comparative evaluation of EUS-guided biliary drainage and percutaneous drainage in patients with distal malignant biliary obstruction and failed ERCP. Dig Dis Sci 2015;60:557-565.

54. Bapaye A, Dubale N, Aher A. Comparison of endosonography-guided vs. percutaneous biliary stenting when papilla is inaccessible for ERCP. United European Gastroenterol J 2013;1:285-293.

55. Artifon EL, Aparicio D, Paione JB, et al. Biliary drainage in patients with unresectable, malignant obstruction where ERCP fails: endoscopic ultrasonography-guided choledochoduodenostomy versus percutaneous drainage. J Clin Gastroenterol 2012;46:768-774.

56. Harada N, Kouzu T, Arima M, Asano T, Kikuchi T, Isono K. Endoscopic ultrasound-guided pancreatography: a case report. Endoscopy 1995;27:612-615

57. Fujii-Lau LL, Levy MJ. Endoscopic ultrasound-guided pancreatic duct drainage. J Hepatobiliary Pancreat Sci 2015;22:51-57.

58. Takano $\mathrm{S}$, Ito $\mathrm{Y}$, Oishi $\mathrm{H}$, et al. A retrospective analysis of 88 patients with pancreaticogastrostomy after pancreaticoduodenectomy. Hepatogastroenterology 2000;47:1454-1457.

59. Haddad LB, Scatton O, Randone B, et al. Pancreatic fistula after pancreaticoduodenectomy: the conservative treatment of choice. HPB (Oxford) 2009;11:203-209.
60. Tyberg A, Sharaiha RZ, Kedia P, et al. EUS-guided pancreatic drainage for pancreatic strictures after failed ERCP: a multicenter international collaborative study. Gastrointest Endosc 2016 Jul 25 [Epub]. http://dx. doi.org/10.1016/j.gie.2016.07.030

61. Chen YI, Levy MJ, Moreels TG, et al. An international multicenter study comparing EUS-guided pancreatic duct drainage with enteroscopy-assisted endoscopic retrograde pancreatography after Whipple surgery. Gastrointest Endosc 2016 Jul 25 [Epub]. http://dx.doi.org/10.1016/ j.gie.2016.07.031.

62. Barkay O, Sherman S, McHenry L, et al. Therapeutic EUS-assisted endoscopic retrograde pancreatography after failed pancreatic duct cannulation at ERCP. Gastrointest Endosc 2010;71:1166-1173.

63. Will U, Meyer F, Manger T, Wanzar I. Endoscopic ultrasound-assisted rendezvous maneuver to achieve pancreatic duct drainage in obstructive chronic pancreatitis. Endoscopy 2005;37:171-173.

64. Papachristou GI, Gleeson FC, Petersen BT, Levy MJ. Pancreatic endoscopic ultrasound-assisted rendezvous procedure to facilitate drainage of nondilated pancreatic ducts. Endoscopy 2007;39 Suppl 1:E324-E325.

65. Itoi $\mathrm{T}$, Kikuyama $\mathrm{M}$, Ishii $\mathrm{K}$, Matsumura $\mathrm{K}$, Sofuni $\mathrm{A}$, Itokawa $\mathrm{F}$. EUS-guided rendezvous with single-balloon enteroscopy for treatment of stenotic pancreaticojejunal anastomosis in post-Whipple patients (with video). Gastrointest Endosc 2011;73:398-401.

66. Kikuyama M, Itoi T, Ota Y, et al. Therapeutic endoscopy for stenotic pancreatodigestive tract anastomosis after pancreatoduodenectomy (with videos). Gastrointest Endosc 2011;73:376-382.

67. Kurihara T, Itoi T, Sofuni A, Itokawa F, Moriyasu F. Endoscopic ultrasonography-guided pancreatic duct drainage after failed endoscopic retrograde cholangiopancreatography in patients with malignant and benign pancreatic duct obstructions. Dig Endosc 2013;25 Suppl 2:109-116.

68. Bataille L, Deprez P. A new application for therapeutic EUS: main pancreatic duct drainage with a "pancreatic rendezvous technique". Gastrointest Endosc 2002;55:740-743.

69. Keenan J, Mallery S, Freeman ML. EUS rendezvous for pancreatic stent placement during endoscopic snare ampullectomy. Gastrointest Endosc 2007;66:850-853.

70. Saftoiu A, Dumitrescu D, Stoica M, et al. EUS-assisted rendezvous stenting of the pancreatic duct for chronic calcifying pancreatitis with multiple pseudocysts. Pancreatology 2007;7:74-79.

71. Cooper ST, Malick J, McGrath K, Slivka A, Sanders MK. EUS-guided rendezvous for the treatment of pancreaticopleural fistula in a patient with chronic pancreatitis and pancreas pseudodivisum. Gastrointest Endosc 2010;71:652-654.

72. Itoi T, Sofuni A, Tsuchiya T, et al. Initial evaluation of a new plastic pancreatic duct stent for endoscopic ultrasonography-guided placement. Endoscopy 2015;47:462-465.

73. Oh D, Park do H, Cho MK, et al. Feasibility and safety of a fully covered self-expandable metal stent with antimigration properties for EUS-guided pancreatic duct drainage: early and midterm outcomes (with video). Gastrointest Endosc 2016;83:366-373.e2.

74. Francois E, Kahaleh M, Giovannini M, Matos C, Deviere J. EUS-guided pancreaticogastrostomy. Gastrointest Endosc 2002;56:128-133.

75. Kahaleh M, Yoshida C, Yeaton P. EUS antegrade pancreatography with gastropancreatic duct stent placement: Review of two cases. Gastrointest Endosc 2003;58:919-923.

76. Ryou M, Mullady DK, Dimaio CJ, Swanson RS, Carr-Locke DL, Thompson CC. Pancreatic antegrade needle-knife (PANK) for treatment of symptomatic pancreatic duct obstruction in Whipple patients (with video). Gastrointest Endosc 2010;72:1081-1088.

77. Tessier G, Bories E, Arvanitakis M, et al. EUS-guided pancreatogastrostomy and pancreatobulbostomy for the treatment of pain in patients with pancreatic ductal dilatation inaccessible for transpapillary endoscopic therapy. Gastrointest Endosc 2007;65:233-241.

78. Ergun M, Aouattah T, Gillain C, Gigot JF, Hubert C, Deprez PH. Endoscopic ultrasound-guided transluminal drainage of pancreatic duct obstruction: long-term outcome. Endoscopy 2011;43:518-525. 
79. Baron TH, Vickers SM. Surgical gastrostomy placement as access for diagnostic and therapeutic ERCP. Gastrointest Endosc 1998;48:640-641.

80. Thompson CC, Ryou MK, Kumar N, Slattery J, Aihara H, Ryan MB. Single-session EUS-guided transgastric ERCP in the gastric bypass patient. Gastrointest Endosc 2014;80:517.

81. Kedia P, Kumta NA, Widmer J, et al. Endoscopic ultrasound-directed transgastric ERCP (EDGE) for Roux-en-Y anatomy: a novel technique. Endoscopy 2015;47:159-163.

82. Kedia P, Sharaiha RZ, Kumta NA, Kahaleh M. Internal EUS-directed transgastric ERCP (EDGE): game over. Gastroenterology 2014;147:566568. 